\title{
On coupling global biome models with climate models
}

\author{
Martin Claussen \\ Max-Planck-Institut für Meteorologie, Bundesstr. 55, D-20146 Hamburg, Germany
}

\begin{abstract}
The BIOME model of Prentice et al. (1992; J. Biogeogr. 19: 117-134), which predicts global vegetation patterns in equilibrium with climate, was coupled with the ECHAM climate model of the Max-Planck-Institut für Meteorologie, Hamburg, Germany. It was found that incorporation of the BIOME model into ECHAM, regardless at which frequency, does not enhance the simulated climate variability, expressed in terms of differences between global vegetation patterns. Strongest changes are seen only between the initial biome distribution and the biome distribution computed after the first simulation period, provided that the climate-biome model is started from a biome distribution that resembles the present-day distribution. After the first simulation period, there is no significant shrinking, expanding, or shifting of biomes. Likewise, no trend is seen in global averages of land-surface parameters and climate variables. Significant differences in the results of the climate-biome model are found when single-year and multi-year climatologies are compared regardless whether climate and biome model are used in an off-line mode or are interactively integrated. It is concluded that a biome model should be coupled with a climate model in the following way: firstly, the climate model should be integrated over several years; secondly, a biome distribution should be computed from the corresponding multi-year simulated climatology; finally, land-surface parameters are to be deduced from the biome distribution as boundary condition of the climate model for a subsequent integration, and so on until an equilibrium is established. Starting the climate-biome model from a biome map which drastically differs from today's global distribution of biomes, but keeping present-day ocean temperatures fixed, it takes several iterations until the model finds a new equilibrium differing from the present-day vegetation distribution in certain parts of the globe. This study indicates that the results of the climatebiome model are dependent on the initial land-surface conditions.
\end{abstract}

KEY WORDS: Atmosphere-biosphere interaction - Bio-geophysical feedback - Global climate-biome model Global vegetation patterns - Vegetation-climate equilibria

\section{INTRODUCTION}

The climate system consists of several subsystems which interact in a complex, nonlinear way at a wide range of time scales. Although the sensitivity of climate simulations to changes in vegetation patterns is well documented (e.g. Mintz 1984), little attention has been paid to the interactive integration of biosphere and atmosphere. By contrast, the interaction between other components of the climate system, mainly atmosphere and ocean, has been studied quite intensively during the last few years (e.g. Cubasch et al. 1992). So far, global vegetation schemes have been used to compute global vegetation patterns, and even potential vegetation shift due to a possible greenhouse gas induced cli- mate warming from climate simulations in a diagnostic (or 1-way) mode (e.g. Prentice \& Fung 1990, Monserud \& Leemans 1992, Monserud et al. 1993, Claussen \& Esch 1994).

Perhaps the first and so far the only attempt to incorporate continental vegetation as a dynamic component of a global climate model was undertaken by Henderson-Sellers (1993). In her study, a simplified Holdridge scheme was used which is a static, diagnostic vegetation model. As an important result, Henderson-Sellers found the vegetation scheme to be a stable component of the global climate system without any discernable trends being observed over the integration period. Differences between simulations with and without interactive vegetation turned out to be rather small. Unfor- 
tunately, the interactive integration was carried out over a rather short period of 5.6 yr due to hardware problems. Hence Henderson-Sellers did not study the problem of coupling vegetation with climate models in great detail. Therefore, the technical problems of integrating a combined climate-vegetation model will be addressed in this paper.

In the next section, the 2 components of the interactive model, a general circulation model of the atmosphere and a vegetation prediction scheme as biospheric component, are briefly presented. Since no global dynamic vegetation models exist at present, the biospheric component consists of a biome model which predicts vegetation zones (or, equivalently, biomes) which are in equilibrium with climate. In the subsequent section, the method of combining climate and biome model is discussed.

The central purpose of this study is to explore the consequences of varying the frequency of asynchronous coupling of a climate model with a biome model and to analyse the way the combined climate-biome model finds its own equilibrium. Therefore, in a first experiment, the climate-biome model is initialized with a global biome distribution which resembles that of present-day climate. Several integrations are performed to analyse the effects of varying frequency of coupling the atmospheric with the biospheric component on variability and trends of global vegetation patterns, land-surface parameters, and climate variables.

Using the experience gained in the first experiment, a second experiment is set up starting from a global biome pattern which drastically differs from today's distribution. This experiment should indicate how sensitive the climate-biome model is to initial disturbances and whether it finds a new equilibrium state. This problem is associated with the question in which parts of the globe vegetation changes remain stable. However, the reader is asked not to overinterpret the results of this study. It is a study of processes rather than an exercise in predicting realistic global vegetation patterns. It should, nevertheless, provide guidance in designing such an exercise.

\section{CLIMATE MODEL AND BIOME MODEL}

\section{The climate model}

The climate model ECHAM, developed at the MaxPlanck-Institut für Meteorologie in Hamburg, Germany, is taken as the atmospheric component of the combined climate-biome model. The model physics as well as its validation is described in detail by Roeckner et al. (1992). In this study, ECHAM is run at T21 reso- lution, hence the grid at which the vertical transports between the atmosphere and the surface are computed has a resolution of $5.6^{\circ} \times 5.6^{\circ}$, i.e. ca $600 \mathrm{~km} \times$ $600 \mathrm{~km}$ at the equator. The climate model ECHAM (level 3) is able to simulate most aspects of the observed time-mean circulation and its intraseasonal varability with remarkable skill (Roeckner et al. 1992). Nevertheless, there are a few problems. For example, during the respective summer season, there is too much precipitation over South Africa and Australia and off the west coast of Central America, whereas the rainfall over India is underestimated during the summer monsoon season. There is a lack of precipitation over the Northern Hemisphere continents during summer, for example over the United States, over Europe, and over the dry regions of Asia. In these areas, the boundary-layer temperatures are generally too high with the largest error about $6 \mathrm{~K}$.

In the original version of ECHAM (level 3), there are no specific biomes or vegetation types prescribed. Instead, a vegetation ratio is assigned to each grid box using data of Wilson \& Henderson-Sellers (1985); a background albedo (albedo of snow-free land surfaces) is derived from satellite data of Geleyn \& Preuss (1983); and roughness length is computed from the variance of orography (Tibaldi \& Geleyn 1981) and from a vegetation roughness length given by Baumgartner et al. (1977). Also a forest ratio (in analogy to vegetation ratio) from Matthews' (1984) data is prescribed which is used to compute the albedo of snowcovered forested areas. The leaf area index is a global constant. Despite these rather crude representation of vegetation in ECHAM, the global patterns of biomes computed from ECHAM climatology agree quite well with those computed from the IIASA (International Institute of Applied Systems Analysis) climate data (Claussen \& Esch 1994) by using the BIOME model of Prentice et al. (1992).

To allow for coupling with a vegetation model, ECHAM was modified such that arbitrary global data of background albedo, roughness length, vegetation ratio, leaf area index and forest ratio can be specified. Other parameters which control the interaction between plants and atmosphere, such as minimum stomatal resistance, are not explicitly defined in ECHAM. They emerge as a combination of constants and are not easily exchangeable.

\section{The biome model}

Biomes are computed by using the BIOME model of Prentice et al. (1992). This model was chosen because it is based on physiological considerations rather than on correlations between climate distribution and 
biomes as they exist today. Biomes are not taken as given as, for instance, in the Holdridge classification, but emerge through the interaction of constituent plants. Hence the BIOME model can be applied to the assessment of changes in natural vegetation patterns in response to different climate states. However, it is important to note that the BIOME model does not simulate the transient dynamics of vegetation. At best, it provides constraints within which plant community dynamics should operate.

In the BIOME model, 14 plant functional types are assigned climate tolerances in terms of amplitude and seasonality of climate variables. The cold tolerance of plants is expressed in terms of a minimum mean temperature of the coldest month. Some plant types also have chilling requirements expressed in terms of a maximum mean temperature of the coldest month.

The heat requirement of plant types is given in terms of annual accumulated temperatures over $5^{\circ} \mathrm{C}$ for some plant types a threshold of $0^{\circ} \mathrm{C}$ is used. The heat requirement of some shrub types is given by the mean temperature of the warmest month.

The third basic climate tolerance is associated with moisture requirement in terms of annual moisture availability. All plant types, except for desert shrub, have minimum tolerable values of annual moisture availability. Only tropical raingreen also has a maximum tolerable value. The annual moisture availability is defined as ratio of actual evapotranspiration (AET) and potential evapotranspiration (PET). PET basically depends on net radiation, i.e. solar radiative input, radiative cooling, and cloudiness. AET, in addition, requires prescription of precipitation and soil water capacity. Hence for evaluation of annual moisture availability, monthly means of temperature, precipitation, cloudiness, and information on soil water capacity are needed as input variables. (Actually the BIOME model uses sunshine in terms of percentages of possible hours of bright sunshine, i.e. an inverse measure of cloudiness.)

The BIOME model predicts which plant functional type can occur in a given environment, i.e. in a given set of climate variables. Then it selects the potentially dominant plant types according to a dominance hierarchy. Finally, biomes are defined as combinations of dominant types. The dominance hierarchy is an artificial device whose main purpose is to facilitate comparison with the global vegetation classification of Olson et al. (1983).

Prentice et al. (1992) used the IIASA climate data base, described by Leemans \& Cramer (1990), and soil texture data (to estimate soil water capacity) from the FAO soils map (FAO 1974). Their predictions of global patterns of biomes are in fair agreement with the global distribution of actual ecosystem complexes being evaluated by Olson et al. (1983). Where intensive agriculture has obliterated the natural vegetation. comparison of predicted biomes and observed ecosystems is, of course, omitted.

\section{COUPLING CLIMATE MODEL WITH BIOME MODEL}

The coupling of ECHAM with the BIOME model is done in a rather simple way. ECHAM produces monthly means of near-surface temperature, precipitation, and cloudiness. From these data, the BIOME model evaluates climate constraints mentioned in the previous section and, subsequently, a global distribution of biomes using the same grid as the climate model. From the biome map, a global set of surface parameters, i.e. background albedo $\alpha$, roughness length $z_{0}$, vegetation ratio $c_{v}$, leaf area index $L A I$, and forest ratio $C_{F}$, needed in ECHAM, are deduced. With this new set of surface parameters a subsequent integration with ECHAM is performed. The problems are: At which frequency should this iteration be done? and How are the surface parameters allocated to biomes?

\section{Allocation of surface parameters}

Allocation of surface parameters to biomes is done in the following way. Firstly, an albedo $\alpha_{w}$ and roughness length $z_{0 \mathrm{v}}$ of vegetation are allocated to Olson et al.'s (1983) major ecosystem complexes basically following Henderson-Sellers et al. (1986) (for details see Claussen et al. 1994). The forest ratio of each ecosystem complex is a rough first guess from Olson et al.'s description of forest and woodland structure. Leaf area index and vegetation ratio are prescribed following Lieth \& Esser's suggestions (cited in Heise et al. 1988). Allocation of $L A I$ to ecosystem complexes is a problem since they are poorly correlated (G. Esser pers. comm.) It seems more reasonable to infer $L A I$ from data of net primary production (NPP) of vegetation. However, allocation of plant types to NPP is still in progress as a new version of the BIOME model is being developed (I. C. Prentice pers. comm.). Hence, for the time being, $L A I$ and $C_{v}$ are taken as a first guess. This should be sufficient for this study which merely explores the consequences of coupling a biome model with a climate model, but does not pretend to predict realistic global vegetation patterns.

Secondly, Olson et al.'s ecosystem complexes are allocated to Prentice et al.'s biomes (for details see Table 4 in Prentice et al. 1992). This is done by averaging surface parameters of ecosystem complexes (weighted with its relative coverage of continental sur- 
faces) to obtain surface parameters for each biome. (Only $z_{0 v}$ is not directly averaged, but computed from an average of drag coefficients taken at a blending height of $100 \mathrm{~m}$; see Claussen 1991.) The final values are given in Table 1.

Finally, the roughness length $z_{0}$ is computed from $z_{0 \mathrm{v}}$ by

$$
z_{0}=\left(z_{\text {oro }}^{2}+z_{0 v}^{2}\right)^{1 / 2}
$$

according to the specification of roughness in ECHAM. $z_{\text {oro }}$ is the roughness length associated with form drag due to subgrid-scale orography exerted on atmospheric flow. In mountainous areas, $z_{0}$ changes little with vegetation since, there, $z_{\text {oro }}$ is much larger than $z_{0 v}$. The background (surface) albedo $\alpha$ is assumed to be given as

$$
\alpha=c_{v} \alpha_{v}+\left(1-c_{v}\right) \alpha_{s}
$$

where $\alpha_{s}$ is the albedo of bare soil. $\alpha_{\mathrm{s}}$ is taken from ERBE satellite data (Claussen et al. 1994) and assumed to be constant during the iterative coupling of ECHAM with the BIOME model. This assumption implies a rather moderate global influence of changes in vegetation to background albedo, since, in this study, $c_{v} \approx 0.5$ on global average. Moreover, it is questionable whether soil properties remain unaffected by changes in vegetation. Therefore, to explore the consequences of a more direct coupling of background albedo to vegetation, $\alpha=\alpha_{v}$ in a second experiment with the exception that $\alpha=0.35$ is specified for biomes 15 and 16 , hot desert and cool desert, to take into account that bare sand deserts may have albedos larger than sparcely vegetated deserts. (For instance, in the Sahara, an albedo of up to 0.4 is observed.)

\section{Setup of experiments}

In her experiment, Henderson-Sellers (1993) calculated a new vegetation distribution and incorporated it into the climate model at the end of each 1.2 mo period. Such a relatively short period was justified by arguing that the year-to-year variability of all vegetation changes computed in an off-line mode is rather small, roughly $10 \%$ of the continental surface. Claussen (1993) investigated the shift of biomes due to simulated climate variability. He used the BIOME model of Prentice et al. (1992) to estimate global vegetation patterns from climatologies simulated by the climate model ECHAM and he found larger numbers lof some $30 \%$ difference) when comparing biomes evaluated from a single-year simulation and a 10 yr simulation. Hence either the BIOME model is more sensitive to climate variation than the Holdridge scheme, or ECHAM produces larger interannual variance than the NCAR CCM climate model used by HendersonSellers. In any case, it seems worthwhile to explore the consequences of letting the biome model and the climate model interfere at various frequencies. Since the BIOME model is a static model, and since the combined climate-biome model can be used simply to let the system integrate into an equilibrium state, a migration criterion as proposed by Martin (1993) for the coupling of dynamic vegetation models with climate models - a criterion which determines the ratio of spatial and temporal incrementation of both models - can be ignored.

A first experiment is started from a global distribution of biomes which is shown in Fig. 8. This initial biome distribution is specified ad hoc in such a way that it resembles the present-day biome patterns shown in Prentice et al. (1992). From the initial biome distribution, a global set of land-surface parameters is deduced and is incorporated into the climate model. Using this initial distribution of land-surface parameters, 4 series of integrations are set up. Firstly, climate model and biome model are run in an off-line mode for 10 yr, called run $A$. For run $A$, a vegetation distribution and an associated distribution of land-surface parameters is obtained at the end of each 12 mo period; however, the land-surface parameters computed at the end of each 12 mo period are not incorporated into the climate model. Averaging over the first and the last $5 \mathrm{yr}$, differences of biome patterns computed from singleyear and 5 yr climatologies are estimated. In a second 10 yr run, called run $B$, biomes and, subsequently, surface parameters are computed and incorporated into the climate model at the end of each year, i.e. in an online or 2-way interactive mode. In a third 20 yr run, called run $C$, information is exchanged between submodels every 5 yr. Hence biomes are estimated from simulated climate data averaged over 5 yr. Land-surface parameters deduced from these biome distributions are incorporated in the climate model to start a subsequent 5 yr run. In the fourth run, called run D, the same is done, but for a $10 \mathrm{yr}$ period. The last run was stopped after 20 yr of integration.

In a second experiment, a drastic change in vegetation patterns is initially prescribed: all desert is replaced by tropical rain forest and all rain forest, tropical seasonal forest, and savanna, by desert. (This initial biome distribution is depicted in Fig. 11.) The landsurface parameters following this new initial biome distribution are specified in the the climate model to start a 22 yr integration. In this integration, the establishment of an equilibrium between climate and vegetation is sought. Climate model and biome model are coupled at a frequency of initially 6 and subsequently 4 yr as a result of the first experiment which will be outlined in the following section. 
Table 1. Allocation of surface parameters used in the climate model to biomes specified in the BIOME model of Prentice et al. (1992)

\begin{tabular}{|c|c|c|c|c|c|c|}
\hline Biome no. & Biome name & $\alpha_{v}$ & $L A I$ & $c_{4}$ & $C_{F}$ & $z_{0 v}(\mathrm{~m})$ \\
\hline 01 & Tropical rain forest & 0.12 & 9.3 & 0.96 & 1.0 & 2.000 \\
\hline 02 & Tropical seasonal forest & 0.12 & 4.8 & 0.81 & 0.9 & 2.000 \\
\hline 03 & Savanna & 0.15 & 2.9 & 0.60 & 0.6 & 0.361 \\
\hline 04 & Warm mixed forest & 0.15 & 6.6 & 0.83 & 0.8 & 0.716 \\
\hline 05 & Temperate deciduous forest & 0.16 & 3.5 & 0.59 & 1.0 & 1.000 \\
\hline 06 & Cool mixed forest & 0.15 & 2.6 & 0.51 & 1.0 & 1.000 \\
\hline 07 & Cool conifer forest & 0.13 & 9.1 & 0.96 & 1.0 & 1.000 \\
\hline 08 & Taiga & 0.14 & 4.1 & 0.68 & 0.9 & 0.634 \\
\hline 09 & Cold mixed forest & 0.15 & 2.6 & 0.51 & 1.0 & 1.000 \\
\hline 10 & Cold deciduous forest & 0.14 & 4.1 & 0.68 & 0.9 & 0.634 \\
\hline 11 & Xerophytic woods/shrub & 0.18 & 3.2 & 0.60 & 0.2 & 0.111 \\
\hline 12 & Warm grass/shrub & 0.20 & 1.0 & 0.29 & 0.0 & 0.100 \\
\hline 13 & Cool grass/shrub & 0.19 & 1.3 & 0.34 & 0.0 & 0.055 \\
\hline 14 & Tundra & 0.17 & 1.5 & 0.39 & 0.1 & 0.033 \\
\hline 15 & Hot desert & 0.28 & 0.3 & 0.08 & 0.0 & 0.004 \\
\hline 16 & Cool desert & 0.28 & 0.3 & 0.10 & 0.0 & 0.005 \\
\hline 17 & Ice/polar desert & 0.15 & 0.0 & 0.00 & 0.0 & 0.001 \\
\hline
\end{tabular}

\section{TESTING THE FREQUENCY OF COUPLING}

As mentioned in the previous section, the first experiment consists of 4 integrations (run A, B, C, D) which differ by the frequency at which information between climate and biome model is exchanged. These 4 integrations are analysed in terms of trends and differences between global surface parameters, climate constraints, interannual variability of biome patterns, and structure of biome patterns.

\section{Variability of biome patterns}

Fig. 1 depicts the interannual differences, $\Delta$, of biome distributions. $\Delta$ is defined as the total area, in term of percentage land surface (Antarctica excluded), in which biomes differ when comparing 2 global biome distributions. For example, the point between abscissa labeis 0 and 1 indicates that for almost $35 \%$ of the continental surface (Antarctica excluded), biomes of the distribution evaluated at the end of the first $12 \mathrm{mo}$ period and of the initial biome distribution are different. The full line indicates differences between biome patterns computed from climate simulations in an offline mode, run $A_{i}$ the dashed line refers to results from the coupled climate-biome model in run B.

From Fig. 1, it is obvious that the largest change is seen between the initial biome distribution and the biome distribution computed after the first period of climate integration, in the following referred to as the first iteration. After the first year, interannual differences do not exhibit a significant trend, neither for the off-line nor for the on-line mode. Excluding the first iteration, the average interannual difference amounts to $27.1 \%$ and $25.7 \%$ in the off-line and on-line mode, respectively. When applying a Student's $t$-test, it is seen that there is no significant difference between these average values.

Fig. 2 is the same as Fig. 1, except that the differences $\Delta$ between successive $5 \mathrm{yr}$ integrations are shown (run C). As also seen in Fig. 1, the largest change (here $27.5 \%$ ) occurs at the first iteration. Sub-

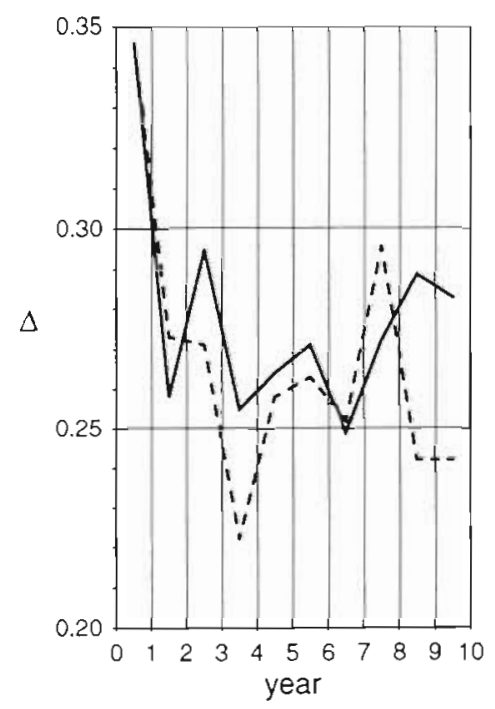

Fig. 1. Interannual changes in the predicted percentages of continental vegetation (Antarctica excluded) for run A (solid line) in which climate and biome model operate separately (in an off-line mode) and for run $B$ (dashed line) of the combined climate-biome model. 'Year 0 ' is used for the initial biome distribution. For definition of $\Delta$, see text 


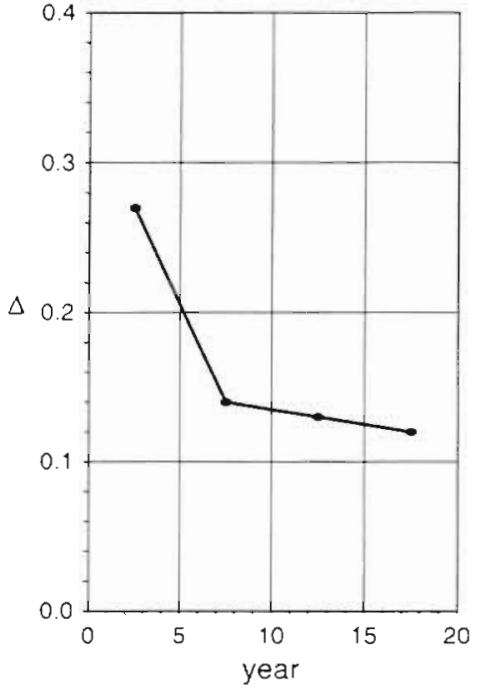

Fig. 2. As Fig. 1, except pentadal changes in run $\mathrm{C}$ in which climate and biome model interfere at a 5 yr period

sequent differences are smaller (here $13.35 \%$ on average). In contrast to runs $\mathrm{A}$ and $\mathrm{B}$, run $\mathrm{C}$ exhibits a significant trend (at $5 \%$ significance level), but this trend is quite small (less than $7 \%$ land area per $5 \mathrm{yr}$ ). When biomes are computed from first and the last 5 yr of the off-line mode run $A$ and of the on-line mode run $B_{1}$ it is found that differences between successive 5 yr climatologies amount to $13.39 \%$ and $13.07 \%$, respectively. Moreover, when comparing all combinations of $5 \mathrm{yr}$ climatologies, differences randomly vary between 12.5 and $15.8 \%$. Hence it can be concluded that differences between biome distributions from various 5 yr integrations are insignificant, regardless of whether computation is done in an off-line mode or in different on-line modes.

Not shown here as a figure are results from the $20 \mathrm{yr}$ integration run $\mathrm{D}$, in which biomes have been computed from the first and the last $10 \mathrm{yr}$ and where new surface parameters are incorporated into the climate model after the first $10 \mathrm{yr}$. The difference $\Delta$ between the initial biome distribution and that computed from the climatology of the first $10 \mathrm{yr}$ amounts to $25.8 \%$, and that between biomes from the first and the second 10 $\mathrm{yr}, 12.6 \%$. Moreover, when comparing the latter biome distribution with the distribution computed from a $10 \mathrm{yr}$ average over results of run $B$, then differences of $12.0 \%$ and $12.6 \%$ are found. These numbers are within (albeit at the upper limit of) the 9 to $12 \%$ range which Claussen (1993) found by comparing various biome distributions computed from various $10 \mathrm{yr}$ integrations with ECHAM both at T21 and T42 resolution, all done in an off-line mode.

In summary, it can safely be stated that incorporation of the BIOME model into the climate model ECHAM does not enhance the simulated variability, expressed in terms of differences between distributions of vegetation or, equivalently, climate zones. Moreover, the frequency at which the biome and the climate model interfere does not significantly alter the degree of interannual, pentadal, or decadal variability.

\section{Global agreement of biome patterns}

The structure of global biome patterns of runs A, B, $C$ and $D$ is analysed using Kappa statistics. Kappa statistics were presented by Monserud \& Leemans (1992) as an objective tool for comparing global vegetation maps. Such maps can result from either compilations of observed spatial patterns or from simulations from models that are global in scope. Monserud \& Leemans (1992) illustrate this method by comparing global maps resulting from applying a modified Holdridge Life Zone classification to current climate and several climate change scenerios. Prentice et al. (1992) used a modified version of the original Kappa statistics to evaluate the performance of their BIOME model. Here, the original Kappa statistics as outlined by Monserud \& Leemans (1992) in detail are applied to explore the similarity of vegetation maps obtained from runs $A, B$, $\mathrm{C}$ and $\mathrm{D}$. In contrast to the analysis of land coverage as done in the previous section, Kappa statistics also indicate if biomes are just shifted without changing their total area occupied. In the latter case, Kappa statistics would indicate poor agreement, whereas the analysis of the previous section would yield no difference.

For details of the Kappa statistics, the reader is referred to Monserud \& Leemans (1992). Here, it should be sufficient to mention that there are 2 Kappa values, a $\kappa$ which indicates global or overall agreement between 2 maps and a vector $\kappa_{1}$ which is a measure of agreement considering a specific biome (number $i$ ). Monserud \& Leemans (1992) proposed threshold values for separating the different degrees of agreement for the Kappa statistics, listed in Table 2.

Table 2. Threshold values for separating different degrees of agreement for Kappa statistics

\begin{tabular}{|clc|}
\hline Lower bound & Degree of agreement & Upper bound \\
\hline$<0.05$ & None & 0.05 \\
0.05 & Very poor & 0.20 \\
0.20 & Poor & 0.40 \\
0.40 & Fair & 0.55 \\
0.55 & Good & 0.70 \\
0.70 & Very good & 0.85 \\
0.85 & Excellent & 0.99 \\
0.99 & Perfect & 1.00 \\
\hline
\end{tabular}


Fig. 3. (a) Global agreement of biome maps from successive years of run $A(\bullet)$ and run $B$ $(\diamond)$. For allocation of Kappa values to a subjective scale see text. (b) Global agreement of biome maps of run $\mathrm{A}(\boldsymbol{\square})$ and run $\mathrm{B}(\square)$ with the initial biome map. ( O) Agreement of biome maps of run $A$ and run $B$, respectively, with the biome distribution from an earlier integration, called run 30 in the text
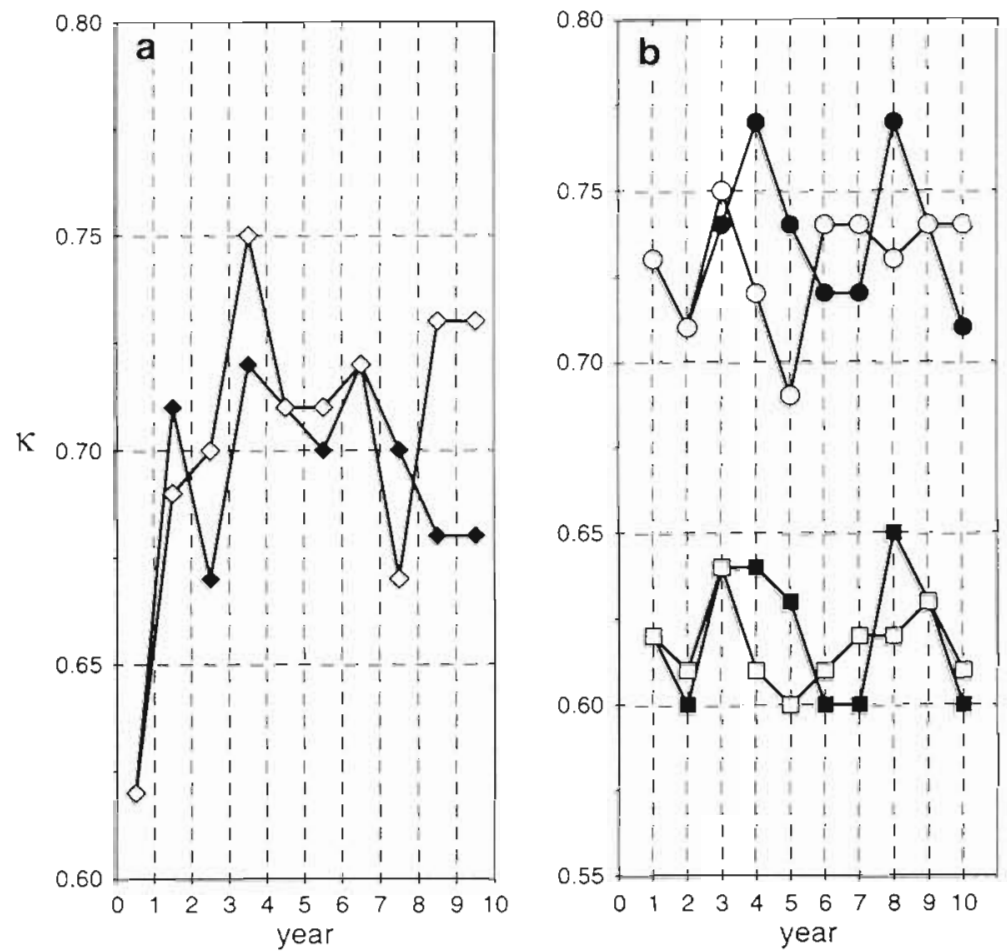

In Fig, 3a, b, the global Kappa values of runs A and B are presented. Fig. 3a shows agreement of biomes maps between 2 successive years of run $A$ and run B. It appears that the agreement between the initial biome map and the biome map computed after the first year of integration is good, $\kappa=0.62$. After the first year, there is no trend, and, on average, $\kappa=0.70$ for run $A$ and $\kappa=0.72$ for run $B$. These average values do not differ significantly.

Fig. 3b depicts agreement of the initial biome pattern and the biome patterns computed at the end of each year of run A and run B. Obviously, there is no apparent trend, and runs $A$ and $B$ both yield $\kappa=0.62$ on average over the 10 yr. Fig. $3 a$ and Fig. $3 b$ show a similar state of affairs from different perspectives. However, there is more information in Fig. 3b.

The curves in Fig. 3b labeled with full and open circles indicate global agreement of maps of run $A$ and run $B$, respectively, with a biome map produced from an earlier $30 \mathrm{yr}$ integration of the climate model ECHAM in its original version level 3 (see Claussen 1993) and shown in Fig. 10. This run is referred to as run 30 in the following. In run 30 , the same sea surface temperature (SST) data are used as for the present runs $A, B, C$ and D. However, different land-surface parameters are taken as discussed below under 'Global surface parameters'. It appears that biome patterns computed from run $A$ and run $B$ agree better with biome patterns deduced from the climate run 30 of ECHAM in its original version than with the initial biome distribution which was merely prescribed, not predicted. Further analysis of the data in Fig. 3b reveals that there is no significant trend and no significant differences between Kappa values estimated from run $A$ and run B.

Results of the analysis of runs C and D, which are not presented as figures here, are the following. It is found that comparison of all biome maps computed from run $C$ and run D yields Kappa values just below $\kappa=0.7$, i.e. biome maps from run $C$ and run $D$ agree better with the initial biome map than biome maps from run $A$ and run $B$. Comparison between biome maps of run $C$ and run $\mathrm{D}$ with that of run 30 yields $0.82<\kappa<0.84$ which is, again, a much better agreement than that of run $A, B$ with run 30 . The biome distribution computed from the second 10 yr of run D is shown in Fig. 9 and should be compared with the biome map in Fig. 10 produced from ECHAM climate run 30. As for runs $A$ and $B$, there is no significant trend in Kappa values after the first iteration. (For run D, statistics have zero degrees of freedom.)

In summary, it appears that biome maps do not change significantly after the first iteration, regardless whether biomes are computed in an off-line or on-line mode with the climate model. Together with the results of the previous section, it can be concluded that, apart from a minor exception, there is no significant shrinking, expanding or shifting of biomes. Moreover, the climate-biome model finds its own equilibrium; the equilibrium biome distribution differs from the 'initial one' 
and resembles more the 'original one', where the 'original one' is a map of biomes obtained by feeding the climate of ECHAM (run 30) in its original version into the BIOME model, while the 'initial one' is the vegetation distribution which has been used to specify landsurface parameters.

\section{Structure of biome patterns}

In the previous section, it was found that there is a difference in global agreement of runs $A$ and $B$ on the one hand, and runs $C$ and $D$ on the other hand. Moreover, there is better agreement of runs $A, B, C$ and D with run 30 than with the initial biome distribution. To analyse this result in more detail, the agreement of individual biomes, i.e. the vector $\kappa_{i}$ is studied.

Fig. 4 depicts the agreement vector $\kappa_{1}$ (for allocation of biome numbers to biome names see Table 1). On the left-hand side of the figure, agreement with run 30 is plotted and on the right-hand side, agreement with the initial biome distribution. Values of $\kappa_{1}$ are averaged over all maps of runs $A, B, C$ and $D$.

At first glance, the left-hand and right-hand sides of Fig. 4 are similar: biomes showing better agreement with biomes of run 30 also exhibit better agreement

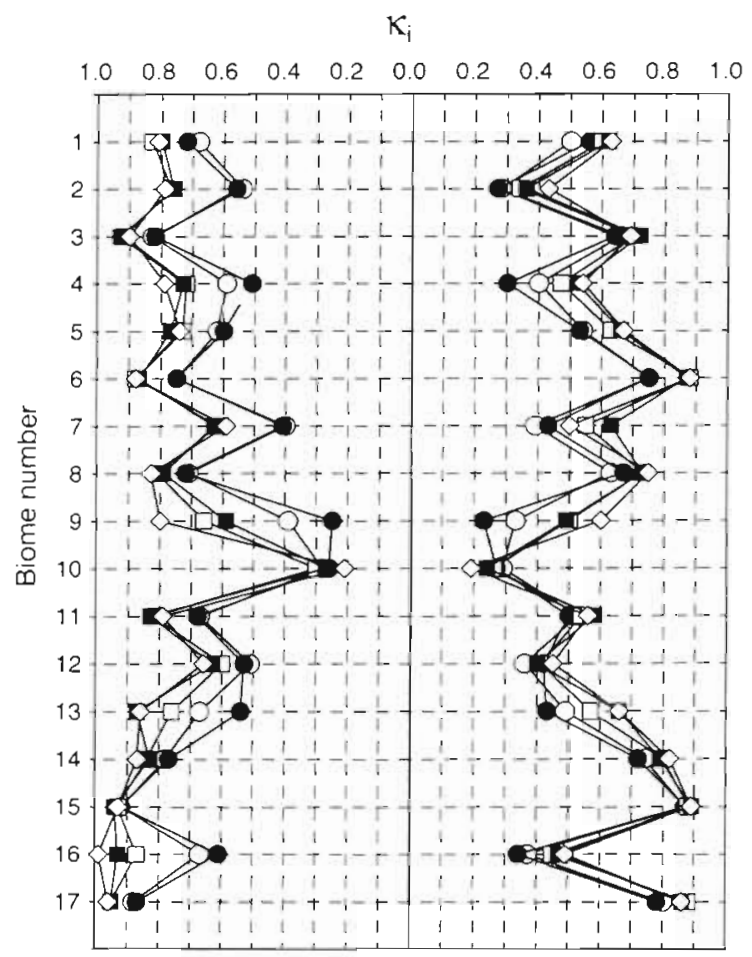

Fig. 4. Agreement of individual biomes from maps of runs A, $B, C$ and $D$ with that of run 30 (left) and with the initial biome map (right). (O) Run $A_{;}(\bullet)$ run $B_{i}(\square)$ run $C_{i}(\square)$ run $D_{;}(\diamond)$ a 5 yr average from run $A$ with biomes of the initial map and vice versa. However, it is also seen why there is better agreement with run 30 than with the initial biome map. When considering the 5 most widespread biomes (which cover the largest portion of continents), it is found that hot desert (biome number 15), cool grass/shrub (14), and polar desert (17) show very good or even excellent agreement when comparing maps of runs $A, B, C$ and $D$ with run 30 as well as with the initial map. By contrast, for savanna (3) and xerophytic woods/shrub (11) much better agreement is found with run 30 than with the initial map.

Concerning the differences between runs $A$ and $B$ and runs $C$ and $D$, it can be inferred from Fig. 4 that all biomes exhibit better agreement when comparing maps of runs $C$ and $D$ with that of run 30 and the initial map (marked by open and full squares in Fig. 4) than when comparing maps of runs $\mathrm{A}$ and $\mathrm{B}$ with the latter (marked by open and full circles). This difference in agreement is particularly large for xerophytic woods/shrub (11) and savanna (3). Other biomes, particularly cold mixed forest (9), show striking differences, but these cover only a relatively small portion of the continental surface (in fact, cold mixed forest covers the smallest portion).

If the biome map computed from the average over the first $5 \mathrm{yr}$ of run $\mathrm{A}$ is compared with the initial map and with that of run 30 , the resulting $\kappa_{1}$ values (marked as open diamonds in Fig. 4) closely resemble those from runs $C$ and $D$, but disagree with those from individual years of run $A$. This result corroborates the following conclusion: there is a consistent difference in biome maps between runs $A$ and $B$ and runs $C$ and $D$. This difference is not due to the interactive integration of climate and biome model. Otherwise, there would be a difference between run $A$ on the one hand and runs $B, C$ and $D$ on the other hand. It is obvious that the difference is caused by using single-year climatologies as in runs $A$ and $B$ instead of multi-year climatologies as in runs $C$ and $D$. If a multi-year climatology is constructed from run $\mathrm{A}$ or $\mathrm{B}$, the corresponding results are closer to those from runs $C$ and $D$ than to those from the original single-year runs $A$ and $B$. The reason for this discrepancy will be discussed below ('Climate variables')

\section{Trends in biome structures}

Since differences in biome structures between runs $A$ and $B$ and runs $C$ and $D$ are detected, it seems worthwhile to check whether there are any differences in trends. Therefore, a trend analysis was applied to percentage land cover of each individual biome and to all $\kappa_{\mu} i=1,2, \ldots, 17$, for runs $\mathrm{A}, \mathrm{B}$ and $\mathrm{C}$, respectively. 
Concerning percentage land cover, no significant trend was found, not even in run $\mathrm{C}$. There is only 1 exception: xerophytic shrub/woods significantly decrease (at $5 \%$ significance level) in run $\mathrm{A}$ if all $10 \mathrm{yr}$ are considered. The trend becomes insignificant if the first year is omitted.

Concerning individual Kappa values $\kappa_{i}$, no significant trend was found (as for global Kappa values $\kappa$ ), except for xerophytic woods/shrub. $\kappa_{11}$ increases slightly when comparing maps of run $\mathrm{C}$ with the initial map, but this is the only exception.

Therefore, it can be concluded that regardless whether the combined climate-biome model or climate and biome model in an off-line mode are integrated and regardless whether the coupling of climate model with biome model is done at an interval of 1 or $5 \mathrm{yr}$, there is no significant shrinking, expanding or shifting of individual biomes

\section{Global surface parameters}

Fig. 5 depicts the time series of global averages of surface parameters, leaf area index $L A I$, vegetation ratio $C_{v}$, forest ratio $c_{F}$, and roughness length $z_{0 v}$, starting with the initial distribution taken as 'year 0 '. The solid lines indicate results of the climate simulation run A in which the initial biome distribution and, hence, the initial distribution of surface parameters is kept fixed, and thus indicate just virtual changes of surface parameters. The dashed lines are the results of integrations with the combined climate-biome model, run B.

From Fig. 5, it is obvious that the largest change in surface parameters occurs at the first iteration, i.e. between the initial distribution and the distribution computed after the first year of integration. Surface parameters of runs A and B do not exhibit any statistically significant trend, even if the initial values are included. Moreover, the hypothesis that the average of global surface parameters over the first $10 \mathrm{yr}$ (initial values of 'year 0 ' excluded) differ significantly can be rejected. Not shown in Fig. 5 is the background albedo which varies only little, except that the initial value is approximately $\alpha \simeq 0.18$ and the subsequent values are $\alpha \simeq 0.19$, both for off-line run $\mathrm{A}$ and on-line run $\mathrm{B}$ integrations.

The difference between surface parameters used for run $\mathrm{A}$ and surface parameters computed from run $\mathrm{A}$ in an off-line mode is rather large when comparing it with the interannual variability of parameters in run $B$ and the virtual interannual variability in run $\mathrm{A}$. In other words, in the present example, the climate model tends to produce its own set of land-surface parameters regardless what is originally prescribed.

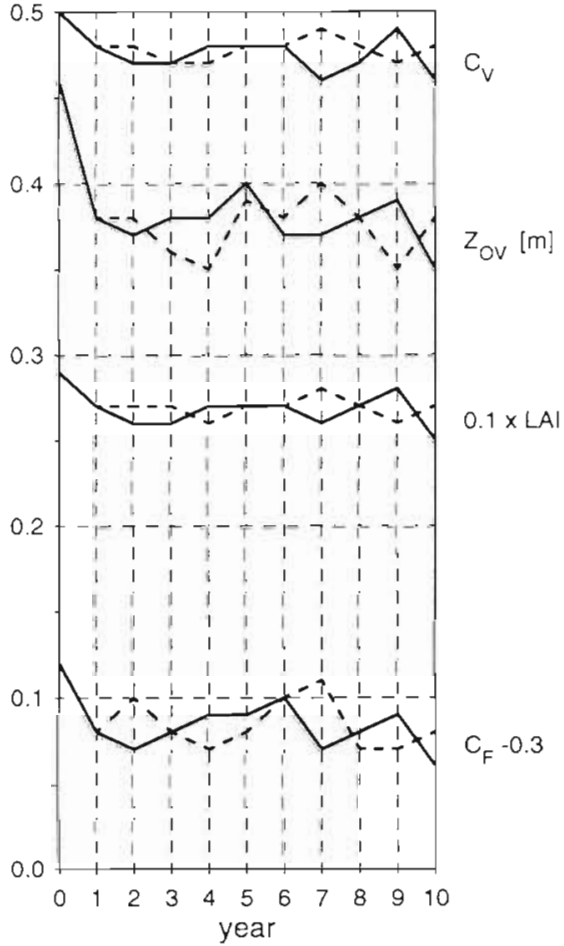

Fig. 5. Global averages of the land-surface parameters vegetation ratio $c_{v}$, vegetation roughness length $z_{0 v}$, leaf area in$\operatorname{dex} L A I$, and forest ratio $C_{F}$, as a function of time. Solid line: virtual changes in run $A_{\text {; }}$ dashed line: changes in run $B$

Fig. 6 depicts global averages of surface parameters computed from run $C$ (solid lines). Here, $c_{v}$ and $C_{F}$ significantly decrease (at $5 \%$ significance level), but if the initial value is disregarded, then no significant trend is left. The dashed lines depict the results of the $20 \mathrm{yr}$ integration run $D$ which are close to those of run $C$.

When comparing surface parameters of runs $C$ and $D$ averaged over the 20 yr of integration (disregarding the initial values at 'year 0'), then there are no significant differences. However, when considering the time averages of surface parameters of either run $A$ or $B$ and those of either run $C$ or $D$, then $c_{v}, c_{F}$, and $z_{0 v}$ differ at a significance level of $5 \%$.

Obviously, incorporation of the BIOME model into the climate model ECHAM does not induce a significant trend in global averages of land-surface parameters. Moreover, using the BIOME model in an off-line or on-line mode does not alter these global averages. However, there is, again, a difference when comparing parameters evaluated from 1 yr climatologies (runs A and B) and multi-year climatologies (runs C and D), corroborating results in the above sections.

The global surface parameters of runs A, B, C and D have to be compared with that of run 30 . In run 30 , the background albedo is $\alpha=0.18$ on global average, i.e. the same global value as in the initial distribution of 


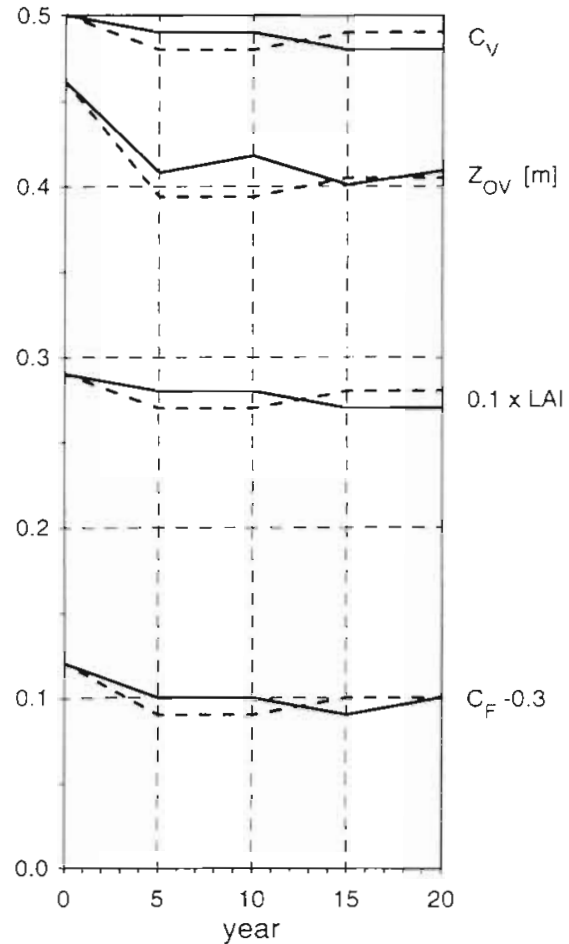

Fig. 6. As Fig. 5, except run C (solid line) and run D (dashed line)

runs $A, B, C$ and D. Furthermore, in run 30 , the leaf area index is set to a constant value of $L A I=4$, the vegetation ratio is generally larger than in runs $A, B, C$ and $D, c_{v}=0.71$ on global average, and the forest ratio is smaller, $c_{F}=0.27$, on global average. Also the roughness length is smaller: the overall roughness length $z_{0}$. which includes form drag due to orography, amounts to $z_{0}=2.539 \mathrm{~m}$ in run 30 which is close to $z_{0}=2.530$,

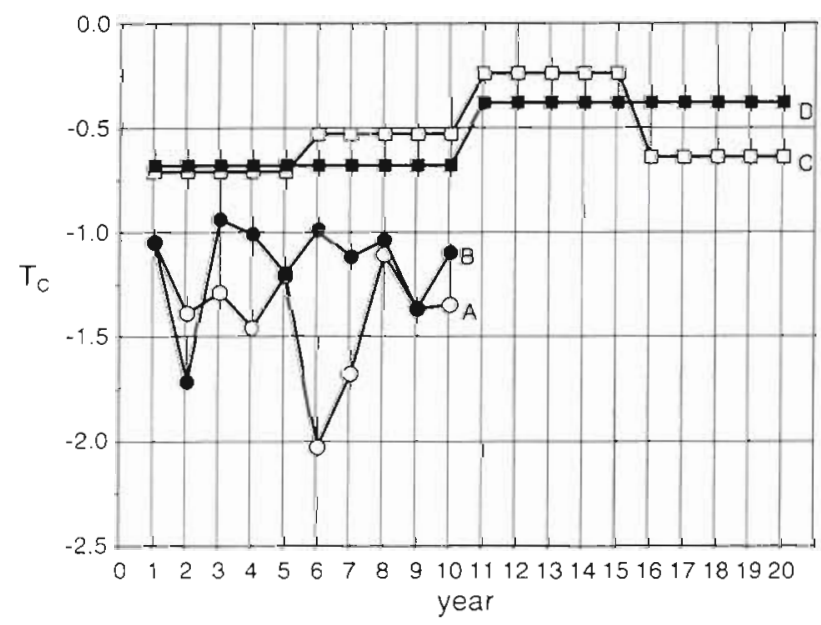

Fig. 7 Mean temperature of the coldest months as a function of integration tume in run $A(O)$, run $B(\bullet)$, run $C(\square)$, and run D
$2.522,2.544$ and $2.540 \mathrm{~m}$ produced by runs $A$ (in an of line mode), $B, C$ and $D$, respectively; but it is much smaller than the initial value of $z_{0}=2.5902 \mathrm{~m}$ used to start runs A, B, C and D. On global average, the land surface parameters of runs $B, C$ and $D$ are closer to the initial values than to that of run 30 , except for the roughness length. Nevertheless, concerning the overall agreement of biome maps, it is just the other way round. Together with the abovementioned result of virtual changes of surface parameters in run $A$, this indicates that, globally, the influence of local changes in land-surface parameters on the atmospheric general circulation is of second order in comparison to dynamical constraints such as the earth's rotation or solar irradiation - provided that the ocean, or more precisely, the SST, is not changed.

\section{Climate variables}

Here, only climate variables are analysed that are used in the BIOME model, i.e. the mean temperature of the coldest month $T_{c}$ the mean temperature of the warmest month $T_{w}$, the sum of temperatures above $0^{\circ} \mathrm{C}$, the sum of temperatures above $5^{\circ} \mathrm{C}$, and the annual moisture availability $m$ which is the ratio of actual and potential evaporation.

In Fig. 7 , averages of $T_{c}$, denoted as $\left\langle T_{c}\right\rangle$, over all continental points are plotted versus time for runs $A$, $B, C$ and $D$. It is obvious that runs $A$ and $B$ reveal much smaller $\left\langle T_{c}\right\rangle$ than runs $C$ and $D$. (This difference is significant at the $1 \%$ significance level.) On the other hand, there is no significant difference between $\left\langle T_{c}\right\rangle$ of run $A$ and of run $B$ when averaged over the $10 \mathrm{yr}$ integration period. The same applies to runs $C$ and $D$. If $\left\langle T_{c}\right\rangle$ is computed from a 5 yr or $10 \mathrm{yr}$ climatology of run $\mathrm{A}$ or $\mathrm{B}$, this $\left\langle T_{c}\right\rangle$ is within the standard deviation of $\left\langle T_{C}\right\rangle$ evaluated from runs $C$ or $D$. This result could have been anticipated: extremes are reduced on average over several years, provided that these extremes occur in different months of different years. The same argument applies to $\left\langle T_{w}\right\rangle$. In fact, $\left\langle T_{\mathrm{w}}\right\rangle$ of runs $\mathrm{A}$ and $\mathrm{B}$ are significantly (at $1 \%$ and $5 \%$ significance level, respectively) larger than of runs $C$ and $\mathrm{D}\left(20.56\right.$ versus $\left.20.28^{\circ} \mathrm{C}\right)$. By contrast, the other variables do not differ significantly between runs $C$ and $B$ nor between $C$ and $A$.

Closer inspection of global distributions of $T_{c}$ reveals differences between runs $A, B$ and $C, D$ to emerge mainly in high latitudes with little effect on biomes. Likewise, differences in $T_{w}$ are found to cause only small differences between biome patterns. On the contrary, most changes in biome patterns occur due to differences in the annual moisture availability. There are regional shifts of moisture patterns, mainly in the 
Table 3. Agreement between biomes computed from a singleyear climatology taken from run $A$ and the second 10 yr integration of run $\mathrm{D}$. For allocation of number to biomes, see Table 1

\begin{tabular}{|ccccc|}
\hline Excellent & Very good & Good & Fair & Poor \\
\hline 14 & 3 & 1 & 2 & \\
15 & 6 & 4 & 9 & \\
16 & 8 & 5 & 10 & \\
17 & 13 & 7 & 11 & \\
& & & 12 & \\
\hline
\end{tabular}

tropics and subtropics, which barely affect the global mean. This can be seen if one compares maps of annual moisture availability together with biome maps. It also becomes evident if Kappa statistics are analysed. An example is given in Table 3.

Worst agreement is indicated for biomes $2,11,12$, i.e. tropical seasonal forest, xerophytic woods, and warm grass, respectively. These biomes cover a rather large portion of the continents and differ mainly by their minimum tolerable annual moisture availability. Biomes 9 and 10, cold mixed forest and cold deciduous forest, are not considered because they cover the smallest portion of the continents. Therefore, it is argued that the differences in biome structures found in the previous sections are due to differences in annual moisture availability.

It is hard to judge whether biome maps of runs $\mathrm{A}$ and $B$ or runs $C$ and $D$ are more realistic, because this experiment is not designed to produce realistic predictions which could be validated. However, it can be stated that runs $C$ and $D$ yield more reasonable results for various reasons. Firstly, biome maps from runs $C$ and $\mathrm{D}$ agree better with the biome map from run 30 which can be considered as ECHAM's original simulation of present-day climatology. Secondly, from the statistical point of view, the BIOME model of Prentice et al. (1992) is formulated to use climatological data. A single year does not constitute a climatology, which is clearly seen when considering extreme values of $T_{\mathrm{c}}$ and $T_{\mathrm{w}}$. Thirdly, from a physical point of view, it seems more reasonable to deduce a climatological value of soil moisture availability from a multi-year climatology because the characteristic time scale of soil moisture changes is almost 1 yr (approximately 8 mo; e.g. Peixoto \& Oort 1992).

\section{A DRASTIC CHANGE IN VEGETATION}

In the first experiment, a biome distribution is initially prescribed which closely resembles today's biome distribution provided by Prentice et al. (1992) as well as the biome distribution produced by an earlier integration (called run 30) of the climate model ECHAM. As a result, the interactive and the off-line mode integrations with the climate-biome model both yield biome distributions which are similar to the initial and the run 30 biome map; in terms of Kappa statistics, they agree very well, almost excellently. These maps, which are shown as Figs. 8, 9 \& 10 (for allocation of colors to biomes, see scale below Fig. 15) are not identical because the allocation of land-surface parameters to biomes has not been tuned. One of the most important results of the first experiment is that the interactive integration of climate and biome model does not enhance simulated climate variability, nor does it induce significant trends, except for the first iteration The first experiment is driven by moderate changes in global biome patterns; therefore, to explore whether adjustment to an equilibrium depends on the initial vegetation pattern, a second experiment was designed in which the combined climate-biome model is initialized with a biome distribution which drastically differs from today's biome map.

The second experiment was set up using the experience gained from the first one. Climate model and biome model are not coupled at a 1 yr interval, and the initial integration is checked for trends before the first iteration is done. The experiment is started with the same initial biome distribution of the first experiment, except that hot desert is replaced by tropical rain forest and tropical rain forest, tropical seasonal forest, and savanna by hot desert (see Fig. 11).

With this initial vegetation distribution, the climate model is run for 6 yr. Biomes and land-surface parameters are computed (in an off-line mode, of course) at the end of each year. When inspecting biome maps, there is considerable variation within the first 3 yr. For illustration, Fig. 12 depicts the interannual differences $\Delta$ and the overall agreement $\kappa$ of successive years. A trend analysis reveals that only when taking the last $3 \mathrm{yr}$ of the $6 \mathrm{yr}$ integration is there no trend in $\Delta$ for any biome, no trend in $\kappa_{i}(i=1,2, \ldots, 17)$, when comparing biome maps of each year with that of run 30 , and no trend in global averages of climate variables. Hence biome patterns and, consequently, land-surface parameters are evaluated from the last 3 yr of the initial integration. The resulting biome map is shown in Fig. 13.

It is striking that all deserts recover at the first iteration, except for the southwest Sahara where xerophytic woods/shrub and warm grass prevail. A change from initially prescribed hot desert to the original tropical rain forest is found only in Indonesia. Obviously the dynamic constraints of the general atmospheric circulation together with the fixed SST dominate over a drastic change in land-surface conditions which is 


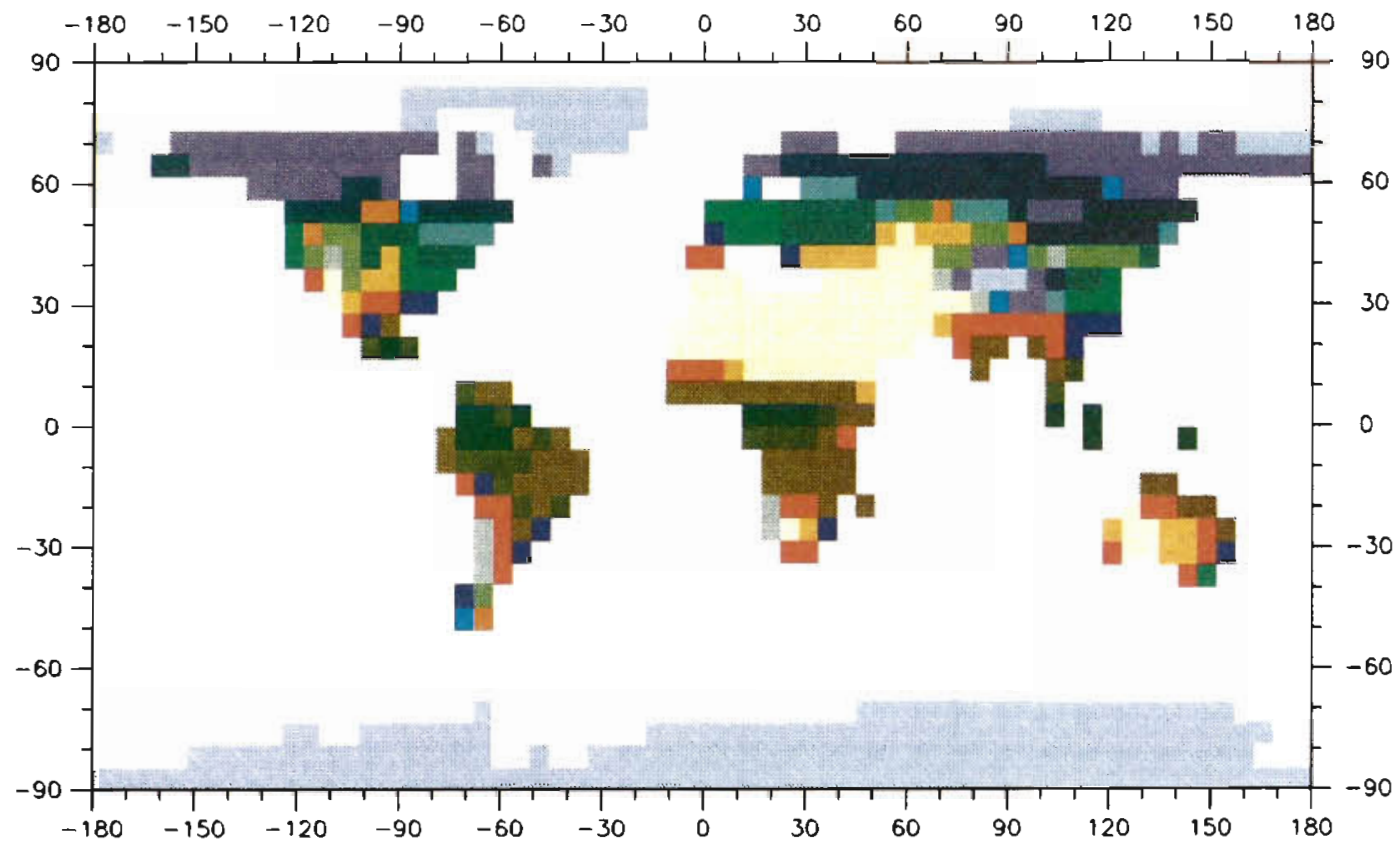

Fig 8. Initial biome distribution of runs $A, B, C$ and $D$.

The color key for all color tigures is shown below Fig 15

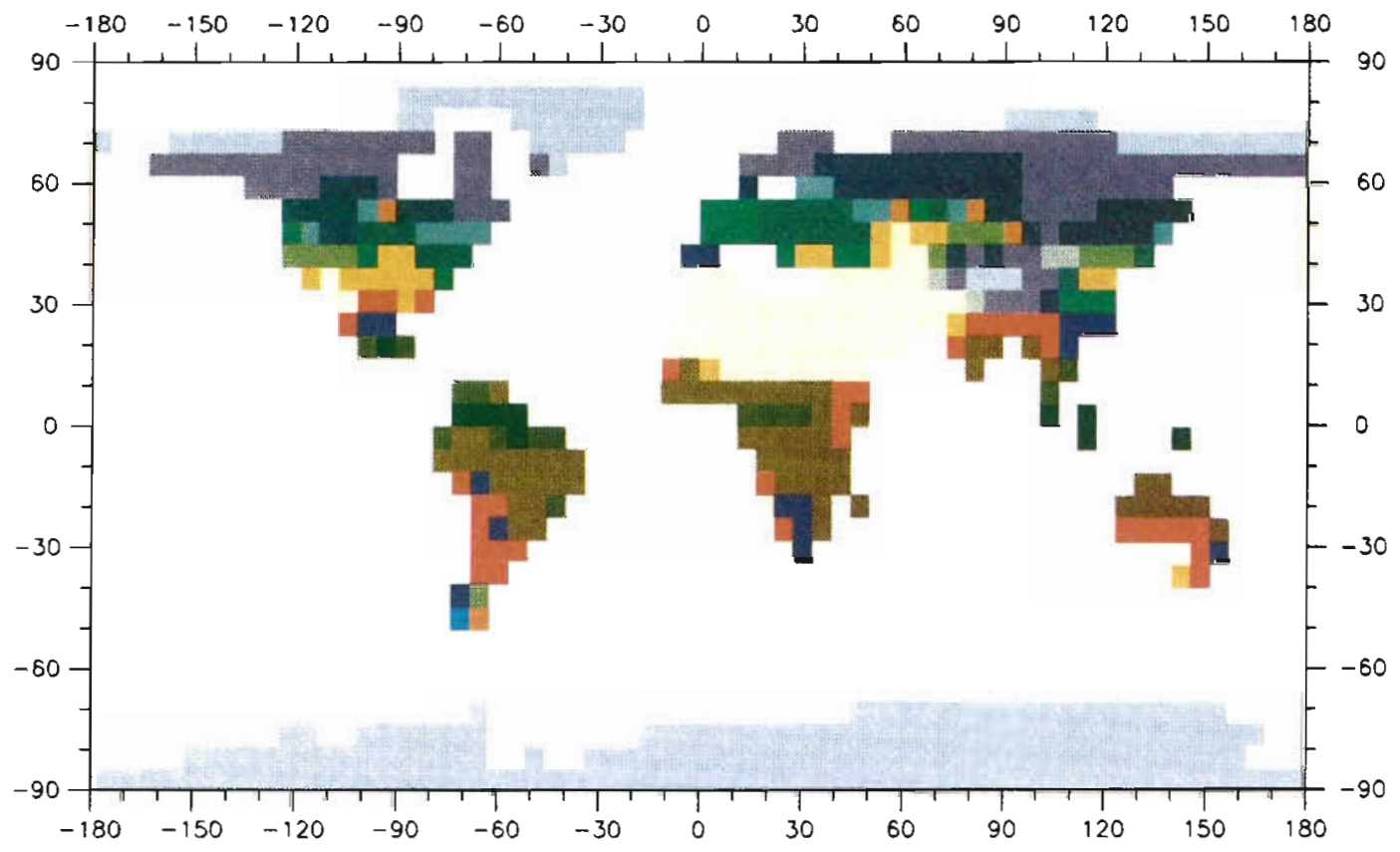

Fig 9 Biome distribution computed trom the second $10 \mathrm{yr}$ integration period of run $\mathrm{D}$ 


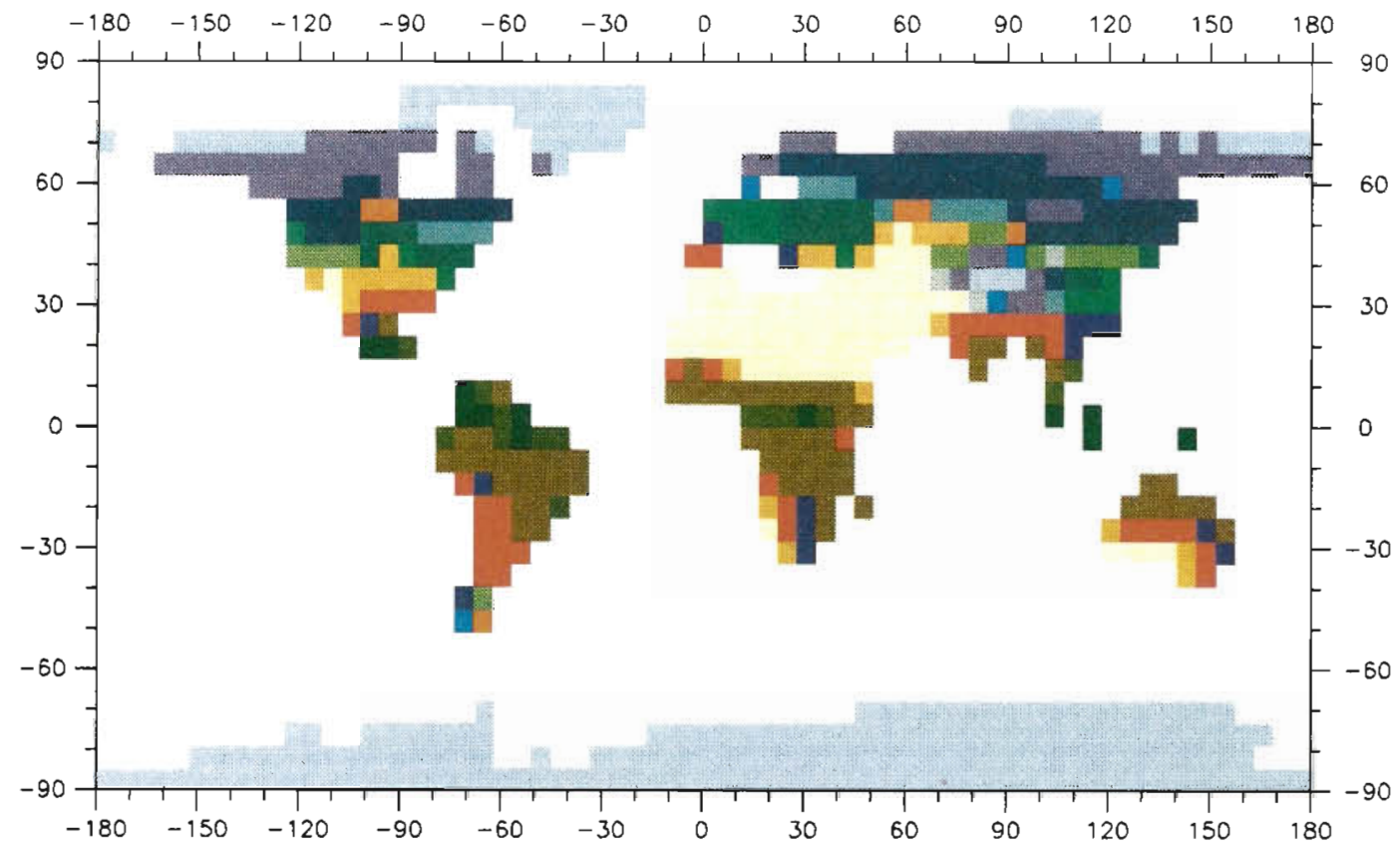

Fig. 10. Biome distribution from an earlier $30 \mathrm{yr}$ integration with the onginal version of the climate model ECHAM3. called run 30 in the text

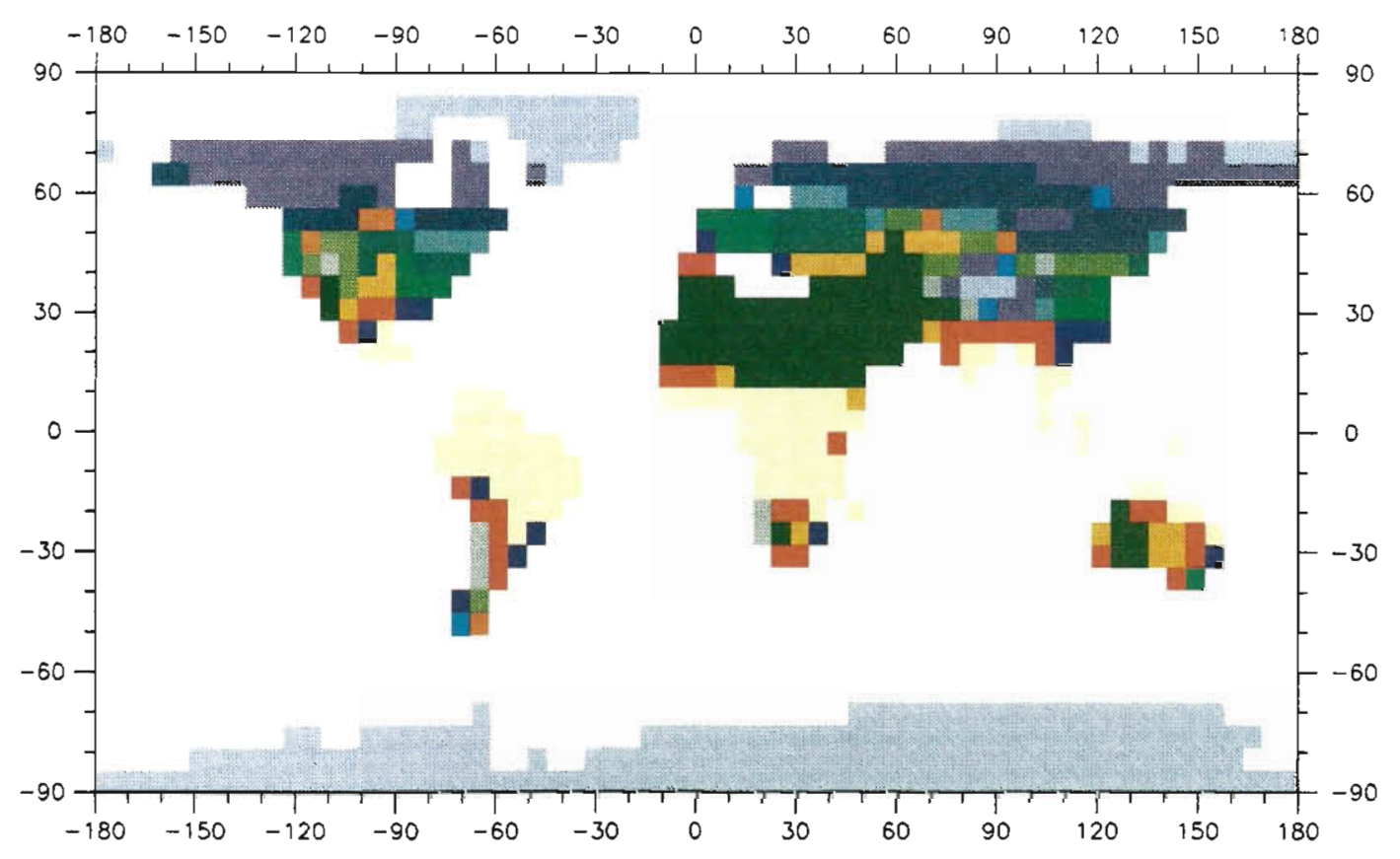

Fig 11 Initial biome distribution of the second experiment 


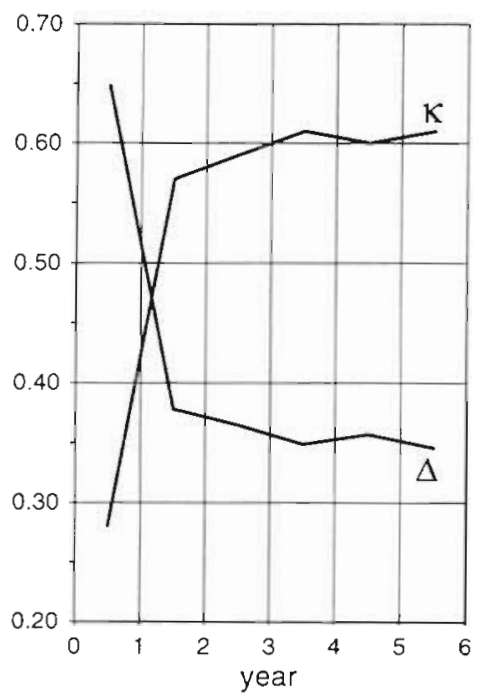

Fig. 12. Difference $\Delta$ in biome maps (for definition of $\Delta$, see text) and global agreement $\kappa$ between the initial 6 successive years of the second experiment

large-scale, not just local as in the first experiment. Only for the SW Sahara have summer precipitation patterns changed over a wide area in comparison with run 30 .

Using the first biome map, Fig. 13, a second integration is started. To speed up computation, the second integration was done for only 4 yr. The first of 4 years is considered an initial phase to let the climate model adjust to new surface parameters. (An inital phase of 1 yr should be sufficient, because the strongest change is expected to have occurred at the first iteration.) A climatology is computed from the last $3 \mathrm{yr}$ which is used to compute a new global distribution of biomes (shown in Fig. 14) and associated land-surface parameters. This procedure is repeated for a third, fourth, and fifth $4 \mathrm{yr}$ integration. The biome map resulting from the last $3 \mathrm{yr}$ of the fifth $4 \mathrm{yr}$ integration is presented in Fig. 15.

The second iteration brings the initial vegetation patterns further back to their original distribution. Rain forest and tropical seasonal forest and savanna have recovered in Latin and South America and most parts of Central Africa (see Fig. 14). Differences from the original biome distribution are still seen in the SW Sahara and in region of Ethiopia where hot desert still remains. But there are more changes which were not prescribed initially. The desert belt has stretched to the east and has invaded the Indian subcontinent. In the region around the Caspian and Aral Seas, where originally (compare with Figs. $8 \& 9$ ) hot desert was simulated, now cool desert and warm grass is found. These differences do not vanish during the following interations (Fig. 15).
Can these differences in biome patterns be traced back to changes in climate variables and, perhaps, to changes in atmospheric circulation patterns? Inspection of climate variables reveals strong differences for precipitation, cloudiness, surface soil moisture, and mean sea-level pressure (MSLP) during summer only. Other variables such as surface and atmospheric 850 hPA temperatures and 500 hPa geopotential heights show only small differences throughout the seasons for all years. As one would expect, surface soil moisture and precipitation are enhanced over the SW Sahara and reduced over India. For cloudiness, the opposite applies. These changes in the hydrological cycle are associated with changes in the general circulation patterns. As indicated by MSLP maps (Fig. 16a, b) the Azores high pressure system is weaker in the combined climate-biome model, and the monsoon trough over the Indian subcontinent is filled up and shifted towards Indonesia. The weakening of the Azores high pressure allows for a stronger and more far-reaching intrusion of southwesterly surface winds into the Sahara, and the increase of MSLP over India characterizes the deterioration of the Indian summer monsoon. How the shift of xerophytic woods/shrubs into the SW Sahara can affect the India summer monsoon and whether this phenomenon is really consistent has to be critically reassessed by high-resolution climate models whose ability to simulate present-day climate can better be trusted than a low-resolution model such as that used here.

The largest changes in the second experiment occur at the first and second iteration. A trend analysis of differences between biome patterns in terms of percentage land cover and Kappa statistics reveals that all trends become insignificant for the last 3 iterations. The same is found to be valid for trends in climate variables. Hence it seems statistically safe to conclude that the combined climate-biome model has found its new equilibrium.

Sensitivities studies, not shown here, reveal that changes in albedo (within the range considered here) more strongly affect the biome patterns than changes in vegetation roughness length. Changes in leaf area index, vegetation and forest ratio have marginal influence.

Summarising this section, after a strong perturbation of vegetation patterns it takes 3 iterations for the combined climate model to approach a new equilibrium state, 2 more than in the first experiment. The new equilibrium differs from the original one. This indicates that for the same orbital conditions and for the same SST, the combined climate-biome model finds different equilibrium solutions depending on the initial vegetation patterns 


\section{CONCLUSION}

The central purpose of this study was to explore the consequences of varying the frequency of asynchronous coupling of a climate model with a biome model and to analyse the way the combined model finds its own equilibrium. To the author's knowledge, this analysis has not previously been undertaken, although this paper is not the first one on interactive integration of a global equilibrium-response vegetation model and a atmospheric general circulation model. Here, the BIOME model of Prentice et al. (1992) and the climate model ECHAM of the Max-Planck-Institut für Meteorologie, Hamburg, have been used as biospheric and atmospheric components of the combined climatebiome model. So far, the following results have been found.

Incorporation of the BIOME model into the climate model ECHAM does not enhance the simulated variability, expressed in terms of differences between global patterns of vegetation or, equivalently, climate zones. This result corroborates Henderson-Sellers' (1993) study, which is interesting because HendersonSellers used a different vegetation scheme and climate model. Hence this result seems to be a general one. The frequency at which the biome and the climate model interfere does not significantly alter the degree of interannual, pentadal, or decadal variability. Together with the analysis from Kappa statistics it appears that all changes occur at the first iteration, after that, apart from a minor exception, there is no significant shrinking, expanding, or shifting of biomes. Likewise, there is no significant trend found in global averages of land-surface parameters and climate variables.

It has been seen that, when started from a biome distribution which is similar to today's distribution, the combined climate-biome model finds its own new equilibrium which differs from the initial biome distribution and approaches the biome map from an earlier integration with the original version of ECHAM. On global average, land-surface parameters found during the course of interactive integration of the climatebiome model are closer to the initial distribution than to that of the original ECHAM run, except for roughness length. However, concerning overall agreement between biome maps, it is just the other way round. Since changes in albedo presumably affect local climate more strongly than changes in vegetation roughness length, it can be concluded that the atmospheric global circulation is more strongly affected by dynamical constraints than by small changes in vegetationprovided that ocean surface temperatures are kept constant.

An interesting difference in biome maps computed from single-year and multi-year climatologies has been detected. It is argued that this difference can be attributed to differences in the annual moisture availability. Because the BIOME model relies on long-term statistics, it is more plausible to incorporate the BIOME model into ECHAM at the end of a multi-year period by deducing biomes from an average climatology of that multi-year period, not just from a singleyear period. Moreover, a multi-year period is needed for the hydrological cycle to approach some equilibrium.

Starting the climate-biome model from a biome map which drastically differs from today's global distribution of biomes, it takes 2 more iterations until the model finds its equilibrium, which differs considerably from the present-day vegetation distribution in certain parts of the globe. Afforestation of the Sahara remains stable in the southwestern region of the desert, albeit the originally 'planted' rain forest turns into xerophytic woods and shrub. Interestingly enough, vegetation changes from xerophytic woods/shrub and warm grass to desert in the Indian subcontinent. It is suggested that these changes in vegetation patterns are associated with weakening of the Azores high pressure system and destroying the Indian summer monsoon. However, a detailed analysis is beyond the scope of this paper. Further investigation with a highresolution climate model and integration over longer periods are needed to decide whether this phenomenon is consistent and significant. Only then it will be safe to conclude whether these changes are directly induced by alteration of vegetation, or whether vegetation changes serve as 'the beat of a butterfly's wing' to push climate into a different mode. The present analysis is just a study of more technical aspects. It will be continued to explore the possibility of other stable climate-vegetation equilibria given the present-day SST field.

To predict realistic global vegetation and climate, the climate-biome model has to be optimized. This has not yet been done, because there are several problems. Allocation of land-surface parameters to biomes is more or less a first, although educated and not unrealistic guess. It does not seem to be a bad guess because the climate-biome model yields very good, for some biomes even excellent, agreement with the original version of the climate model. Nevertheless, the allocation could be tuned to yield even better agreement

Before aiming at a realistic prediction of present-day climate with the climate-biome model, an agricultural component of global vegetation has to be introduced. After all, man has modified almost $20 \%$ of the earth's surface. An attempt to include an agricultural component in the BIOME model has been made by Cramer \& Solomon (1993). The new version of the climate model 


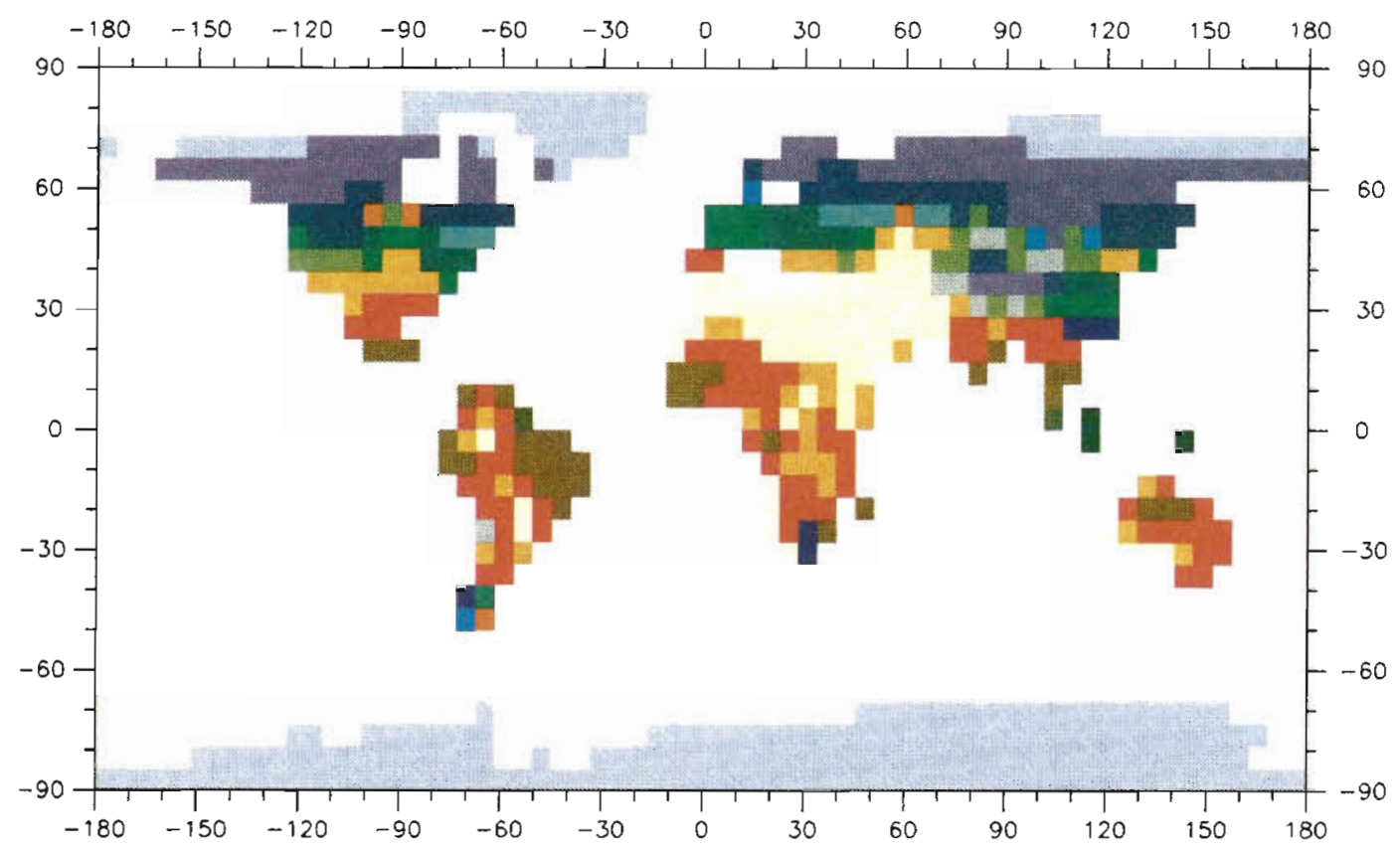

Fig. 13 Biome distnbution computed from an average over Years 4 to 6 of the initial integration period of the second experiment

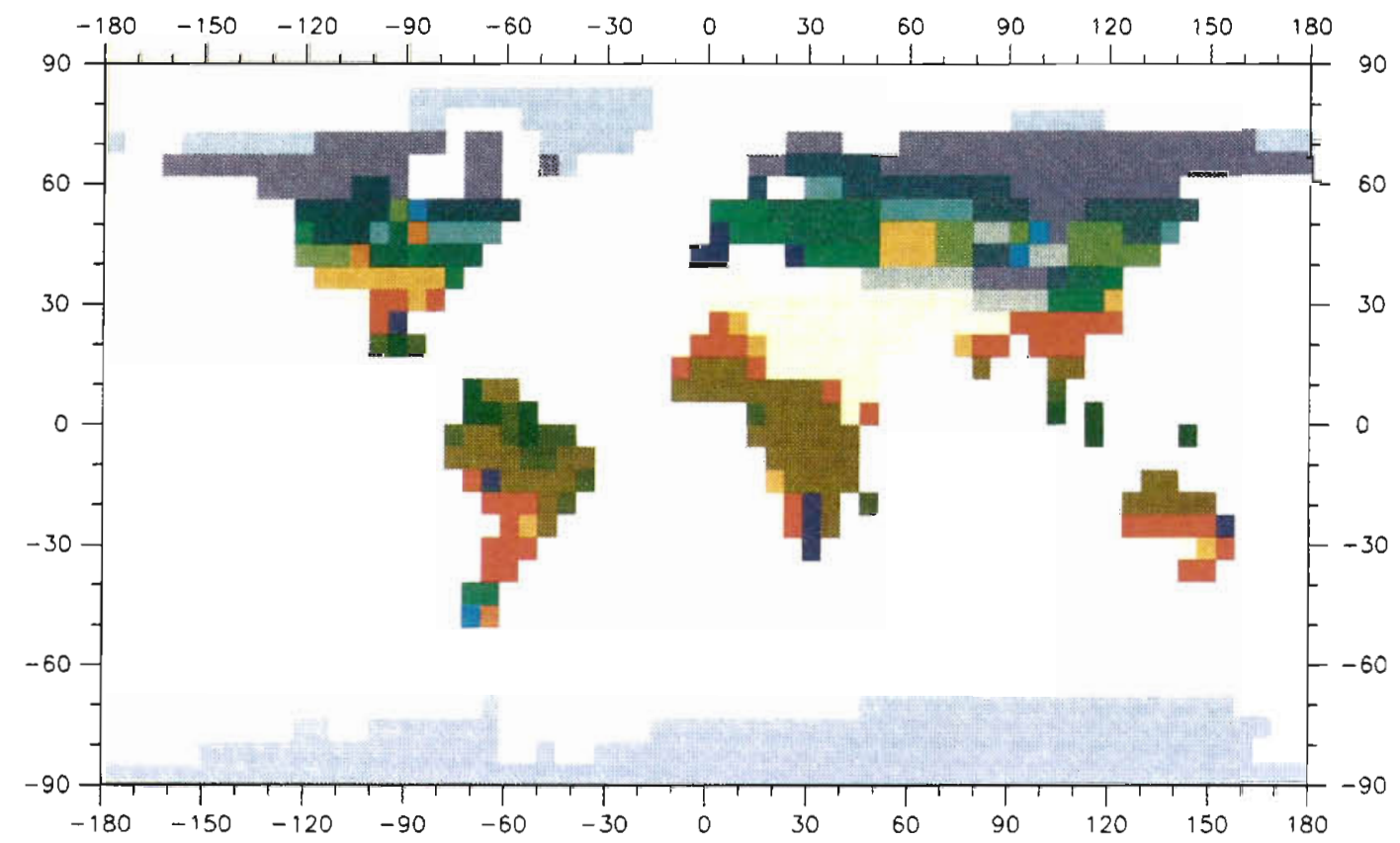

Fig. 14. As Fig 13, except for Years 7 to 8, 1 e the last 3 yr of the second integration period 


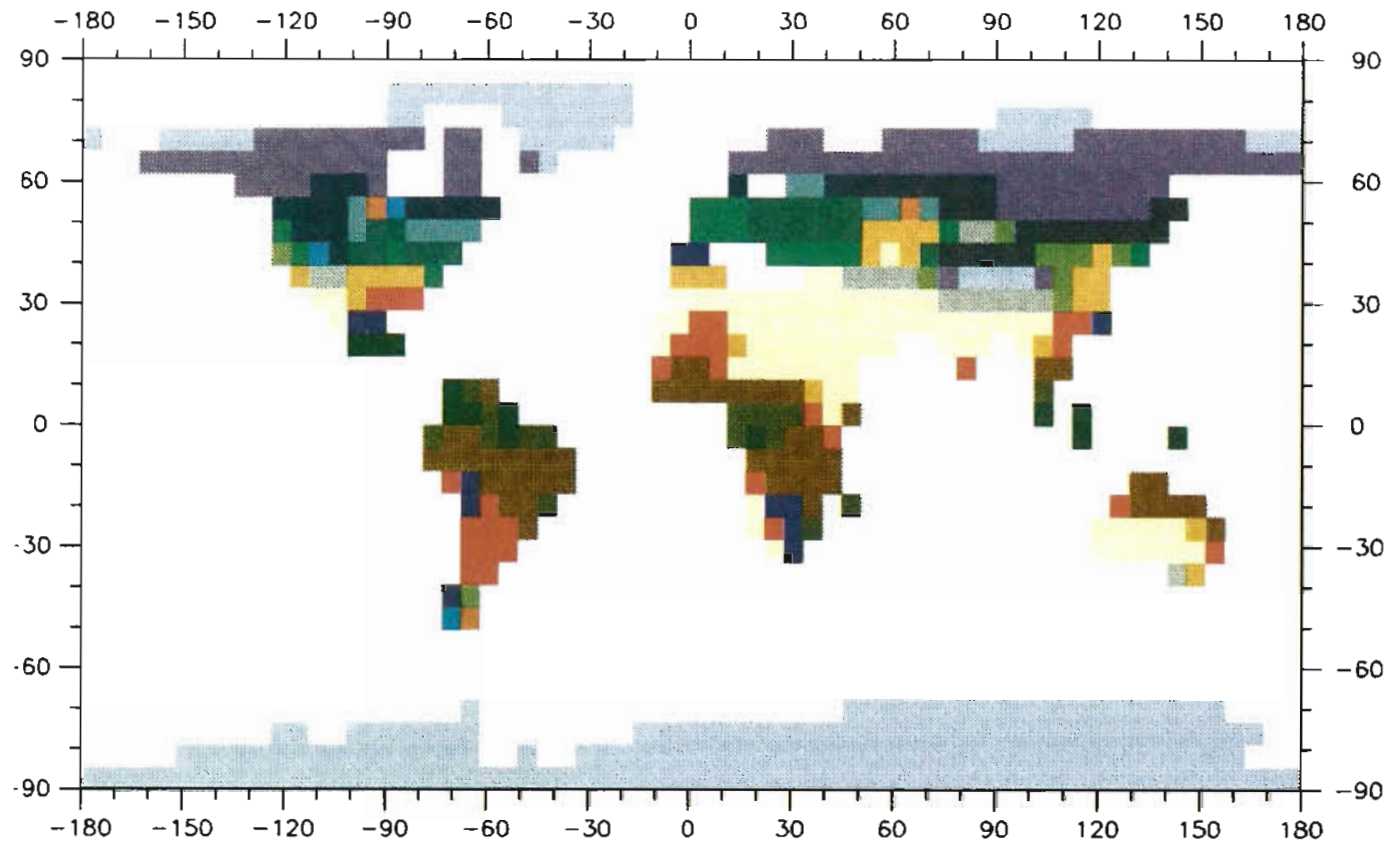

Fig. 15. As Fig. 13, except for Years 20 to 22, i.e. the last 3 yr of the fifth and last integration period

Tropical Rain Forest

Tropical Seasonal Forest

Savanna

Warm Mixed Forest

Temperate Deciduous Forest

Cool Mixed Forest

Cool Conifer Forest

Taiga

Cold Mixed Forest

Cold Deciduous Forest

Xerophytic Woods/Shrub

Warm Grass/Shrub

Cool Grass/Shrub

\section{Tundra}

Hot Desert

Cool Desert

lce/Polar Desert
Key to colors used for biomes in Figs. 8 to 11 and 13 to 15
ECHAM (level 4) will use land-surface parameters which are deduced from Olson et al.'s (1982) map of major ecosystems, including ecosystems strongly affected by man. Hence, the new version of ECHAM will be more suitable as atmospheric component of a combined climate-biome model.

An important aspect of climate variability has been left out of this study: the dynamics of ocean circulation. Up to now, studies of the effect of vegetation changes on climate have been done with an atmospheric circulation model coupled with, at best, an oceanic mixed layer model in which the temperature of the mixed layer is calculated from the heat flux of the surface provided by the atmospheric model, whereas the meridional oceanic heat transport is specified according to the observed SSTH climatology. Work in progress with a coupled global atmosphere-ocean model (Latif, Hoffmann \& Claussen, Max-Planck-Institut für Meteorologie) suggests that deforestation of tropical rain forest induces an increase of sea-surface temperatures in the tropical Western and Eastern Pacific as well as in the tropical Atlantic. Hence it has to be expected that a coupled atmosphere-biosphere-ocean general circulation model (ABOGCM) will exhibit an enhanced variability and will, presumably, adopt equilibrium states which differ from a climate-biome model with fixed ocean temperatures. It is hoped that this study will provide guidance in constructing an ABOGCM. 
a SEA LEVEL PRESSURE (HPa) July 20-22

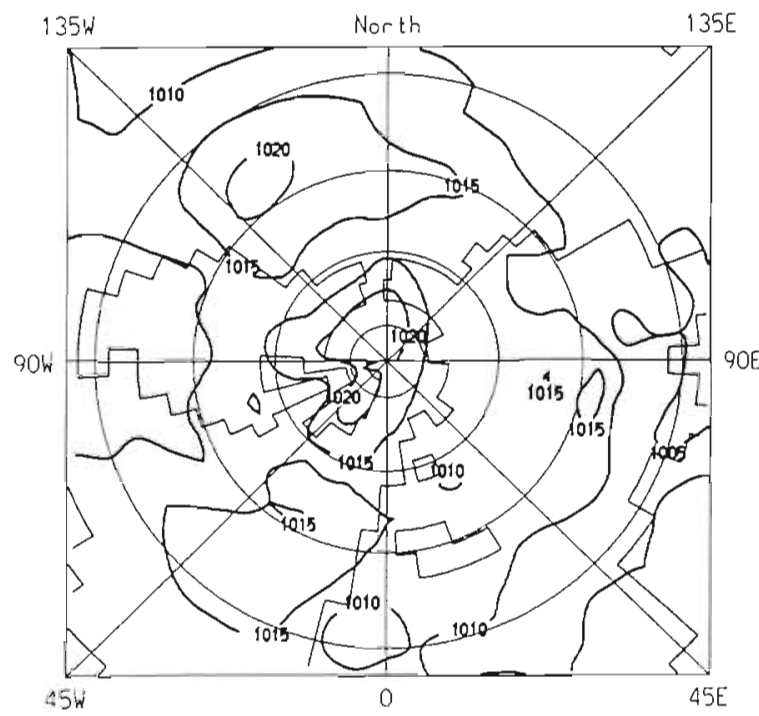

b SEA LEVEL PRESSURE (HPa) July 11-20

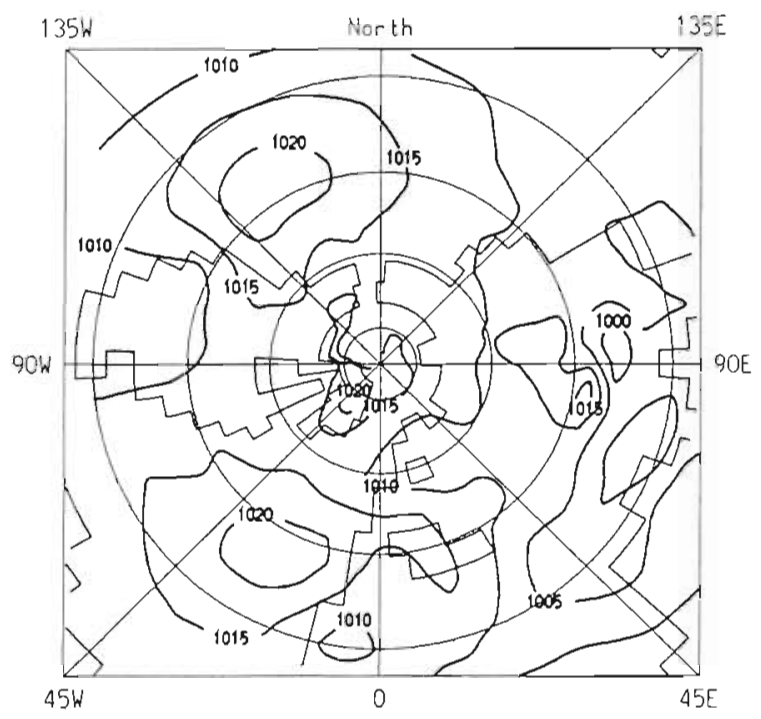

Fig. 16. Northern hemisphere mean sea-level pressure (hPa) in July on average over (a) 3 yr of the second experiment and (b) the first $10 \mathrm{yr}$ of run 30

Acknowledgements. The author thanks Colin Prentice, Dept of Plant Ecology, Lund University, Sweden, for making the biome model available. Thanks are also due to Uwe Schulzweida and Monika Esch, Max-Planck-Institut für Meteorologie, Hamburg, for programming assistance. The author appreciates helpful suggestions by Lennart Bengtsson and Martin Heimann, Max-Planck-Institut für Meteorologie, and by 2 anonymous reviewers.

\section{LITERATURE CITED}

Baumgartner, A., Mayer, H., Metz, W. (1977). Weltweite Verteilung des Rauhigkeitsparameters $z_{0}$ mit Anwendung auf die Energiedissipation an der Erdoberfläche. Meteorol. Rundsch. 30: 43-48

Claussen, M. (1991). Estimation of areally-averaged surface fluxes. Boundary-Layer Meteorol. 54: 387-410

Claussen, M. (1993). Shift of biome patterns due to simulated climate variability and climate change. Report 115, MaxPlanck-Institut für Meteorologie, Hamburg

Claussen, M. Esch, M. (1994). Biomes computed from simulated climatologies. Clim. Dyn. 9: 235-243

Claussen, M., Lohmann, U., Roeckner, E., Schulzweida, U (1994). A global data set of land-surface parameters. Report 135, Max-Planck-Institut für Meteorologie, Hamburg

Cramer, W. Solomon, A. M. (1993). Climatic classification and future global redistribution of agricultural land. Clim. Res. 3: $97-110$

Cubasch, U., Hasselmann, K., Höck, H., Maier-Reimer, E. Mikolajewicz, U., Santer, B. D., Sausen, R. (1992). Timedependent greenhouse warming computations with a coupled ocean-atmosphere model. Clim. Dyn. 8: 55-69

FAO/UNESCO (1974). Soil map of the world 1:5000000. FAO, Paris

Geleyn, J.-F., Preuss, H. J. (1983). A new dataset of satellitederived surface albedo values for operational use at ECMWF. Arch. Meteorol. Geophys. Bioklimatol. Ser. A 32: $353-359$
Heise, E., Jacobs, W., Ketterer, M., Renner, V (1988). Klimasimulation mit atmosphärischen Modellen im Zeitskalenbereich von Monaten. Abschlußbericht des BMFT-Projektes KF 2012 8, Deutscher Wetterdienst, Offenbach

Henderson-Sellers, A. (1993). Continental vegetation as a dynamic component of global climate model: a preliminary assessment. Clim. Change 23: 337-378

Henderson-Sellers, A., Wilson, M.F., Thomas, G., Dickinson, R. E. (1986). Current global land-surface data sets for use in climate-related studies. NCAR Technical Note NCAR/ TN-272+STR, National Center for Atmospheric Research, Boulder, CO

Leemans, R., Cramer, W. (1991). The IIASA database for mean monthly values of temperature, precipitation, and cloudiness on a global terrestrial grid. IIASA Research Report RR-91-18, Laxenburg

Martin, P. (1993). Vegetation responses and feedbacks to climate: a review of models and processes. Clim. Dyn. 8: $201-210$

Matthews, E. (1984). Vegetation, land-use and seasonal albedo data sets: documentation of archived data tape. NASA Technical Memorandum 86107. Goddard Space Flight Center, New York

Mintz, Y (1984). The sensitivity of numerically simulated climates to land-surface boundary conditions. In: Houghton, $\mathrm{J}$ (ed.) The global climate. Cambridge Univ. Press, Cambridge

Monserud, R. A., Leemans, R. (1992). Comparing global vegetation maps with Kappa statistic. Ecol. Modelling 62: $275-293$

Monserud, R. A., Tchebakova, N. M., Leemans, R. (1993) Global vegetation change predicted by the modified Budyko model. Clim. Change 25: 59-83

Olson, J. S., Watts, J. A., Allison, L. J. (1983). Carbon in live vegetation of major world ecosystems. ORNL-5862, Oak Ridge National Laboratory, Oak Ridge, TN

Peixoto, J. P., Oort, A. H. (1992). Physics of climate. American Institute of Physics, New York

Perlwitz, J. (1992). Preliminary results of a global SST anom- 
aly experiment with a T42 GCM. In: Annales Geophysicae, Suppl. to Vol. 10. Abstracts of the VII General Assembly of the European Geophysical Society in Edinburgh, Apr. 6-10, 1992. European Geophysical Society, Katlenburg-Lindau, p. C296

Prentice, I. C., Cramer, W., Harrison, S. P., Leemans, R., Monserud, R. A., Solomon, A. M. (1992). A global biome model based on plant physiology and dominance, soil properties and climate. J. Biogeogr 19: 117-134

Prentice, K. C., Fung, 1. Z. (1990). The sensitivity of terrestrial carbon storage to climate change. Nature 346: 48-51

Roeckner, E., Arpe, K., Bengtsson, L., Brinkop, S., Dümenil, L., Kirk, E., Lunkeit, F., Esch, M., Ponater, M., Rockel, B.,

Editor: G. Esser, Gießen, Germany
Sausen, R., Schlese, U., Schubert, S., Windelband, M. (1992). Simulation of the present-day climate with the ECHAM model: impact of model physics and resolution. Report 93, Max-Planck-Institut für Meteorologie, Hamburg

Tibaldi, S., Geleyn, J.-F. (1981). The production of a new orography, land-sea mask and associated climatological surface fields for operational purposes. ECMWF Tech. Memo. 40. European Centre for Medium Range Weather Forecasts, Reading

Wilson, M. F., Henderson-Sellers, A. (1985). A global archive of land cover and soils data for use in general circulation climate models. J. Climatol. 5: 119-143

Manuscript first received: April 8, 1994

Revised version accepted: August 29, 1994 